


\title{
GÊNESE E EVOLUÇÃO DO PLANALTO DE MARÍLIA (BRASIL)
}

\section{GENESIS AND EVOLUTION OF THE MARÍLIA PLATEAU (BRAZIL)}

\author{
C. A. M. Santos ${ }^{1} \&$ J. O. R. Nunes ${ }^{2}$
}

\begin{abstract}
Resumo - O Planalto de Marília é uma unidade geomorfológica que se destaca na paisagem do centro-oeste do Estado de São Paulo, Brasil. Constitui-se como a zona mais heterogênea do Planalto Ocidental Paulista (morfoescultura onde está inserida). Nele, há o predomínio de formas denudacionais, caracterizando-o como dispersora de drenagem. Típico relevo tabuliforme de centro de bacia sedimentar, caracteriza-se pela horizontalidade da camada geológica que o sustenta. As sucessivas mudanças climáticas ocorridas no Quaternário permitiram a gênese de um grande compartimento de topo alongado e suavemente ondulado, interligado ao domínio das vertentes que se encerram em escarpas, e dando forma a vales intra-escarpas com desníveis que variam de 50 a 80 metros até o limite da ruptura de declive. Para um melhor entendimento das atuais formas de relevo, buscou-se, através de revisão bibliográfica, relaçôes entre tectônica geradora e modificadora da Bacia Bauru, reativaçôes tectônicas de sistemas de falhas e a sedimentação da Formação Marília com a evolução geomorfológica do Planalto homônimo. Utilizou-se o modelo esquemático de relevos tabuliformes de CASSETI (2001), inserindo características específicas do caso analisado. A tectônica que deu origem a Bacia Bauru, aliada aos alinhamentos preexistentes no embasamento da Bacia Sedimentar do Paraná, condicionou a compartimentação e localização das deposiçôes sedimentares do Grupo Bauru, no qual se encontra a Formação Marília. A epirogênese pós-cretácica acelerou a incisão dos talvegues e, pulsos tectônicos, possivelmente reflexos de reativaçóes dos alinhamentos estruturais da Bacia Sedimentar do Paraná, provocaram falhas e juntas na região, colaborando para organização da drenagem e esculturação do relevo.
\end{abstract}

Palavras-chave - Planalto de Marília; Formação Marília; Relevo tabuliforme; Marília-SP; Brasil

1 Doutorando do Programa de Pós-Graduação em Geografia da Universidade Estadual Paulista, Faculdade de Ciências e Tecnologia, Campus de Presidente Prudente-SP; kiomarques@hotmail.com

2 Professor Doutor do Departamento de Geografia da Universidade Estadual Paulista, Faculdade de Ciências e Tecnologia, Campus de Presidente Prudente-SP; joaosvaldo@fct.unesp.br 
Abstract - The Marilia Plateau is an outstanding geomorphological unit located at the midwestern part of the state of Sao Paulo (Brazil). It is the most heterogeneous zone of the Western Paulista Plateau (morphosculpture where it is inserted). On it, the denudational landforms predominate, characterizing it as a drainage disperser area. This area, a typical mesa relief of a sedimentary basin center, is characterized by the horizontality of the geological layer that supports it. Successives Quaternary climatic changes allowed the formation of a large stretched-top, softly-waving compartment, interconnected to the cliffs that ends up on scarps, shaping the intra-scarps valleys with uneveness ranges of 50 to 80 meters to the edge of the slope break. For a better understanding of the present reliefforms, we searched, through literature revision, the relation between tectonics generating and modifying the Bauru Basin, tectonic reactivation of fault systems and sedimentation of the Marilia Formation with the geomorphological evolution of the Marilia Plateau. We used the schematic model of the mesa reliefs proposed by CASSETI (2001), inserting specific characteristics of the analyzed case. The tectonic proccess that raised the Bauru Basin, toghether with pre-existing structural alignments on the Parana Sedimentary Basin basement, conditioned the subdivision and location of the sedimentary deposits of the Bauru Group, into which the Marilia Formation is inserted. The post-Cretaceous epirogenesis accelerated the thalwegs incision and the tectonic pulses, possibly some reflections of structural alignments reactivations of Paraná Sedimentary Basin, which caused faults and joints in the region, contributing to the organization of drainage and relief sculpture.

Keywords - Marilia Plateau; Marilia Formation; Mesa relief; Marília-SP; Brazil

\section{1 - Introdução}

O Planalto de Marília (Fig. 1) é uma unidade geomorfológica em destaque na paisagem do centro-oeste paulista. Ele resistiu às aplainaçôes neogênicas mencionadas por AB'SABER (1969a,b), constituindo-se, assim, em um de seus testemunhos. ROSS \& MOROZ (1996) o denominam Planalto Residual de Marília. Segundo os autores, ele é um prolongamento para oeste do Planalto Residual de Botucatu, desempenhando um vasto planalto de topo aplanado no interflúvio Tietê/Paranapanema delimitado pelo Planalto Centro Ocidental. De acordo com IPT (1981), corresponde à zona mais heterogênea do Planalto Ocidental Paulista, morfoescultura onde se insere.

Assim como os demais planaltos diferenciados (IPT, 1981), o de Marília constitui-se como área dispersora de drenagem. Predominam nesta unidade formas de relevo denudacionais, cujo modelado apresenta-se na forma de colinas com topos aplanados convexos e tabulares, que se desfazem em escarpas festonadas, conforme caminham para os limites do planalto. A dimensão interfluvial média varia de menos de $250 \mathrm{~m}$ a $750 \mathrm{~m}$. As altimetrias que predominam estão entre 500 e $600 \mathrm{~m}$ e as declividades entre 10 e 20\% (ETCHEBEHERE, et al.,2004). Apresenta dissecação média, com vales entalhados e densidade de drenagem variando de média à alta, o que implica um nível de fragilidade que torna a área susceptível a fortes atividades erosivas, sobretudo nas vertentes mais inclinadas.

Como típico relevo tabuliforme de centro de bacia sedimentar, caracteriza-se pela horizontalidade da camada geológica que o sustenta. As sucessivas mudanças climáticas ocorridas no Quaternário permitiram a gênese de um grande compartimento de topo alongado e suavemente ondulado interligado ao domínio das vertentes, que se encerram em escarpas, e dando forma a vales intra-escarpas com desníveis que variam de 50 a 80 metros até o limite da ruptura de declive (Fig. 2). 


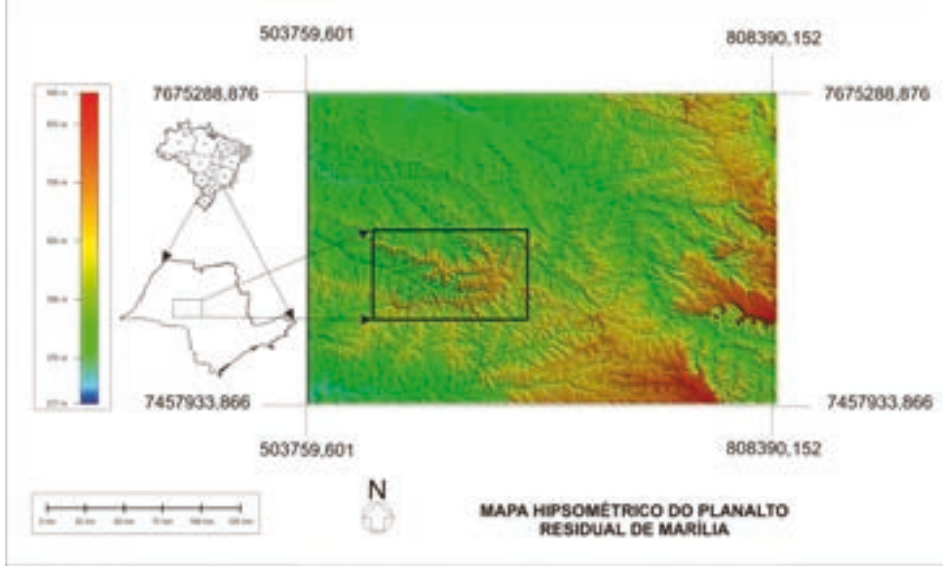

Fig. 1 - Localização do Planalto de Marília no Planalto Ocidental Paulista (SANTOS, 2009). As áreas em vermelho a leste e sudeste correspondem ao reverso das cuestas arenítico-basálticas.

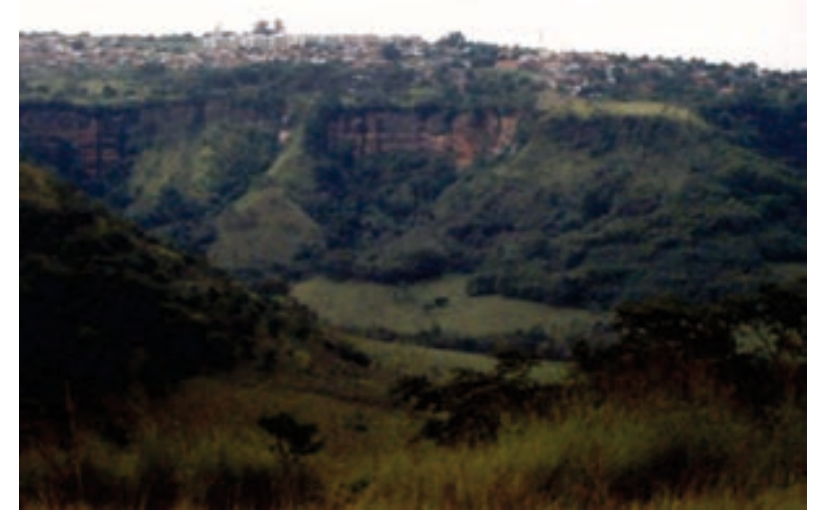

Fig. 2 - Vista do topo do Planalto de Marília. Nota-se a expansão urbana até os limites das escarpas.

Busca-se, nesse trabalho, utilizando-se de revisóes bibliográficas, estabelecer relações entre a tectônica geradora da Bacia Bauru, reativaçóes tectônicas de alinhamentos estruturais e a sedimentação da Formação Marília com a evolução geomorfológica deste planalto. As relaçôes são incluídas como especificidades do caso analisado, no esquema evolutivo de relevos tabuliformes de CASSETI (2001).

O estabelecimento dessas relaçôes é uma tentativa de se entender melhor as atuais formas do relevo do município de Marília-SP, que influenciam e condicionam práticas urbanas e ambientais, como localização de condomínios fechados, de estaçóes de tratamento de esgoto e lixão.

Os resultados obtidos fazem parte do referencial teórico da tese de doutorado em elaboração, na qual se busca confirmar ou refutar, através de dados de traços de fissão em zircão e apatita, as relaçóes obtidas nesse artigo. 


\section{2 - O tectonismo gerador da Bacia Bauru}

Segundo BATEZELLI (2003), a Bacia Bauru (Fig. 3) corresponde a uma entidade geotectônica gerada no Cretáceo Superior por processos de abatimento relacionados à reativação de lineamentos do embasamento pré-cambriano, tendo sido implantada tanto sobre os arenitos do Grupo Caiuá, como sobre os basaltos da Formação Serra Geral.



Fig. 3 - Mapa de distribuição das unidades do Grupo Bauru

(FERNANDES \& COIMBRA, 1996 Mod. apud BATEZELLI et al., 2005).

Possui uma extensão de cerca de 370.000 km e abrange áreas distribuídas pelo Triângulo Mineiro, noroeste do Paraná, sudeste de Mato Grosso do Sul e sul de Goiás. Dessa extensão, $100.000 \mathrm{~km}$ são em território paulista.

A Bacia Bauru é formada no contexto de ruptura do Gondwana, em que há a separação do continente Sul-Americano e Africano. Durante esse contexto tectônico há o derrame de lavas basálticas que dá origem a Formação Serra Geral na Bacia do Paraná (BORGHI, 2002). Ela precedeu e acompanhou a ruptura do paleocontinente (TURNER et al., 1994 apud RICCOMINI, 1997), espalhamento do assoalho oceânico e a deriva continental que acarretaram na separaçáo dos dois continentes e no surgimento do oceano Atlântico Sul.

A porção centro-sul da Plataforma Sul-Americana passa a responder, então, aos efeitos da carga causada pelas rochas basálticas: à subsidência termal e, posteriormente, ao deslocamento da Placa Sul-Americana e sua interaçáo com a Placa de Nazca a oeste (RICCOMINI, 1989, 1995a apud RICCOMINI, 1997).

O autor op. cit. afirma mudar o contexto intracratônico da Bacia do Paraná, cedendo lugar para novos tipos de deposiçôes sedimentares, como resposta ao novo contexto tectônico. 


\section{3 - A sedimentação da Formação Marília}

No topo da sequência sedimentar do Grupo Bauru (Fig. 4), a Formação Marília diferencia-se das demais formaçóes do Grupo, principalmente, pelo seu agente cimentante e ambiente de sedimentação: possui abundância de carbonato de cálcio e foi depositado por leques aluviais em condiçôes de aridez a semi-aridez.

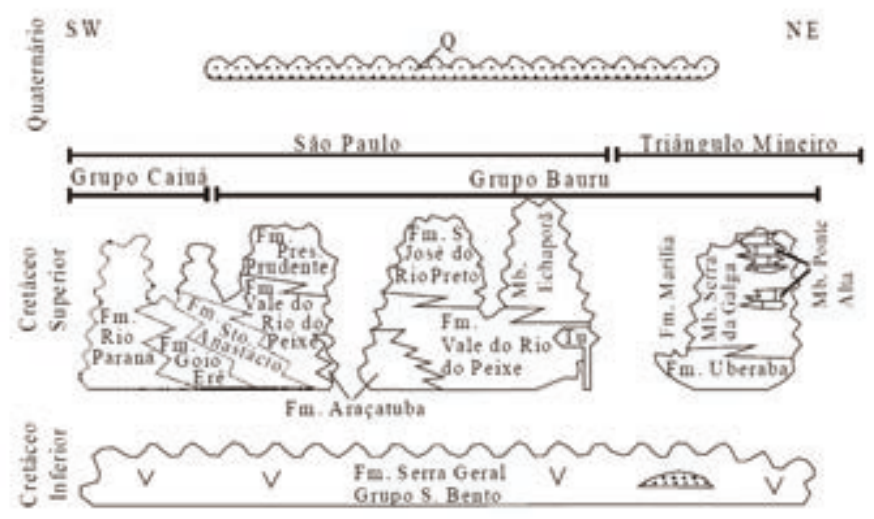

Fig. 4 - Relações estratigráficas na parte oriental da Bacia Bauru. TU = analcimitos Taiuva (adaptado de FERNANDES, 1998 e FERNANDES \& COIMBRA, 1999 apud GRAVINA et. al., 2002).

Ocorre extensivamente no Triângulo Mineiro, na região sul de Goiás, sudeste de Mato Grosso do Sul, e formando os planaltos de Marília e Monte Alto no estado de Sáo Paulo. Apresenta um comportamento transgressivo, ou seja, ultrapassa os limites geográficos da Formação Adamantina e sobrepóe-se diretamente aos basaltos da Formação Serra Geral (BARCELOS, 1984).

De acordo com PAULA e SILVA et al. (2003), a Formação Marília ocorre exclusivamente em superfície, e tem área de exposição restrita à porção sudeste da bacia, e na região de Monte Alto. Em subsuperfície, registra espessuras máximas de 233 m na cidade de Lupércio, 201 m em Marília, 192 m em Álvaro de Carvalho e 185 m em Quintana.

Segundo SOARES et al. (1980) apud BARCELOS (1984, p. 100), foram os primeiros autores a apresentar formalmente a Formação Marília, definindo-a

[...] como unidade composta por arenitos grosseiros a conglomeráticos, com grãos angulosos, teor de matriz variável, seleção pobre e ricos em feldspatos. Esses sedimentos ocorrem em bancos com espessura métrica entre 1 e 2 metros, maciços ou em acamamento incipiente subparalelo descontínuo, raramente apresentando estratificação cruzada de médio porte, com seixos concentrados nos estratos cruzados. Ocorre também raras camadas descontínuas de lamitos vermelhos.

RICCOMINI (1997) escreve acerca de um tectonismo gerador e deformador da Bacia Bauru. Ele cita seu trabalho de 1995a, onde afirma que a posição da bacia e de seu depocentro, distantes da margem continental, as características de cada processo e os esforços 
associados, sugerem que esses fatores tiveram interferência direta na bacia, tanto na fase geradora como na modificadora. $\mathrm{O}$ tectonismo na margem continental teria atuado na sedimentação em termos do controle do nível de base regional.

$\mathrm{O}$ autor $o p$. cit. atesta a existência de pulsos tectônicos durante a sedimentação, dentre outros fatos, pela distribuição dos leques aluviais da Formação Marília estar vinculado aos alinhamentos do Rio Paranapanema, Ibitinga-Botucatu e do Rio Moji-Guaçu, contendo seixos de rochas do embasamento pré-cambriano (gnaisses, granitos, anfibolitos, quartzitos) situadas nos flancos leste e sudeste da bacia. Esses pulsos podem ser reflexos de reativaçóes de alinhamentos estruturais do embasamento da Bacia Sedimentar do Paraná.

A afirmação anterior é atestada por BARCELOS (1984), ao comentar sobre as condiçôes de sedimentação do Membro Echaporã, divisão que o autor faz da Formação Marília.

[...] parecem ter sido de alta energia e de deposição rápida em forma de leques aluviais, em que as sucessivas mudanças dos lobos deposicionais causaram a coalescência lateral e a subsidência produziu o empilhamento vertical dos diversos lobos. Esses sedimentos foram depositados por drenagem anastomosada temporária e torrencial. Submetidos durante longo tempo à condição de clima semi-árido, desenvolveram-se paleossolos carbonáticos e calcretes nodulares (p. 123).

Percebe-se que a mesma tectônica que deu origem a Bacia Bauru, aliada aos alinhamentos estruturais preexistentes no embasamento da Bacia Sedimentar do Paraná, condicionaram a compartimentação e localização das deposiçóes sedimentares do Grupo Bauru. Essa ideia é reforçada por FÚLFARO (1974, p. 135), ao afirmar que

[...] No Cretáceo Superior, época da deposição da Formação Bauru, o alinhamento Paranapanema representa uma barragem aos sedimentos deste ciclo. A Formação Bauru, resultado de um maior levantamento do arco da Canastra e da margem oriental da bacia (SUGUIO, 1973), é barrada ao sul pela ocorrência deste alto estrutural não havendo ao sul desta linha ocorrência de depósitos expressivos a ele correlacionáveis.

Pensa-se, dessa maneira, que essa influência tectônica direcionando a direção, fluxo, taxa e, principalmente, local da sedimentação, mesmo que indiretamente, tenha colaborado para a gênese do Planalto de Marília.

\section{4 - Evolução do Planalto de Marília}

Nessa etapa do trabalho utiliza-se o modelo esquemático de evolução de relevos tabuliformes de CASSETI (2001). Através dele, faz-se apontamentos acerca das especificidades do Planalto de Marília.

Típico de centros de bacias sedimentares, suas camadas caracterizam-se por serem horizontalizadas ou subhorizontalizadas, associadas ou não a derrames basálticos intercalados. No caso estudado, como visto anteriormente, a Formação Serra Geral é o embasamento que acaba dando origem a Bacia Bauru e a sedimentação do grupo homônimo, no qual a Formação Marília está no topo da sequência sedimentar. 
AB'SABER (1969a) afirma que no Cretáceo Superior, quando há a gênese do Grupo Bauru, ocorre o último re-embaciamento da Bacia do Paraná. Para ele, o encerramento da sedimentação é essencial para entender a história geomorfológica regional, em que se passa de uma história puramente geológica para uma fisiográfica e geomorfológica.

CASSETI (op. cit.) afirma que, embora elaborado por mecanismos morfoclimáticos, o relevo reflete diretamente a participação da estrutura, o que resultaria em formas estruturais características de sequências sedimentares horizontalizadas. Fato esse em que se acredita ter sido condicionada indiretamente pela tectônica. Contudo, ressalta-se uma especificidade deste planalto: suas formas estruturais evoluíram em camada sedimentar única, portanto, controlada fundamentalmente por diferenças de resistência litológica.

Chapadóes, chapadas e mesas são as formas mais comuns em estruturas concordantes. De acordo com CASSETI ( $o p$. cit.), elas são mantidas à superfície por camadas basálticas ou por sedimentos litificados de maior resistência quando submetidas a processos de pediplanação (e isso está relacionado com condiçôes ambientais áridas a semi-áridas que deram origem a superfície erosiva). Para FERNANDES (2010), o Planalto de Marília origina-se por inversão de relevo, em que a forma de deposição do carbonato de cálcio colabora para a formação dos calcretes (responsáveis pela manutenção da resistência litológica).

CASSETI (2001) admite, para o caso brasileiro, no início da formação de relevos tabuliformes uma fase climática úmida responsável pela organização da drenagem em um pediplano em ascensão por esforços epirogenéticos.

AB'SABER (1969a, p. 1), em trabalho realizado acerca do ritmo da epirogênese pós-cretácica no estado de São Paulo, afirma que ela tem fundamental importância para compreender "a marcha dos fenômenos denudacionais e tectônicos responsáveis pela compartimentação topográfica dos planaltos paulistas”. De acordo com o autor, essa tectônica respondeu pelo soerguimento global do edifício geológico-estrutural do estado.

Tem-se, dessa forma, esquematicamente, a seguinte evolução na elaboração do relevo:

1 - Organização do sistema hidrográfico em fase climática úmida associada a efeitos epirogenéticos;

A orientação do sistema fluvial, segundo o modelo adotado, sugere duas possibilidades: influência da imposição do mergulho das camadas geológicas ou à topografia resultante do processo de pediplanação que condiciona inclinação em direção ao nível de base local ou regional.

A primeira está relacionada com o caráter de sinéclise que a Bacia do Paraná assume durante sua evolução numa escala espacial mais abrangente, e as condiçóes de sedimentação da Formação Marília numa abrangência mais local. A segunda relaciona-se com as aplainaçóes neogênicas em território paulista (AB'SABER, 1969a).

Além disso, há o reflexo causado na topografia pelos alinhamentos estruturais do embasamento cristalino que, através de reativações tectônicas, ocasionaram falhas e fraturas nas rochas cretácicas, por onde teriam se iniciado a incisão dos talvegues. Juntamente a isso, acredita-se que essa epirogênese, a qual se refere o autor anteriormente citado, tenha acelerado o ritmo da erosão e a incisão dos talvegues.

Para RICCOMINI (1997), o tectonismo deformador sucedeu-se ao preenchimento sedimentar da bacia, deixando registradas estruturas como falhas e juntas, que podem ser interpretadas como resultantes de dois regimes transcorrentes correlacionáveis à 
mega-estruturação geológica do Estado de São Paulo, sendo o último provavelmente vinculado à atividade neotectônica regional (ETCHEBEHERE, et al., 2004). Falhas e juntas mais antigas teriam orientado a organização do sistema hidrográfico e início da esculturação do Planalto de Marília.

Em levantamentos executados pelo autor na região balizada pelas cidades de São Manuel, Cafelândia e Echaporã, foram cadastradas falhas e juntas seccionando os depósitos das formações Marília e Adamantina. O caráter tectônico e pós-sedimentar dessas estruturas é atestado por afetarem rochas inteiramente litificadas e pela persistência em área dos padróes reconhecidos. Falhas com estrias ocorrem de forma localizada, principalmente na região de Marília-Echaporã (RICCOMINI, 1997).

2 - Devido aos esforços epirogenéticos considerados, há uma tendência de aprofundamentos dos talvegues e de aprofundamentos de seus vales;

Por se tratar de um tipo de relevo elaborado em sequência sedimentar única, a manutenção da resistência litológica é processada pelas variaçóes de concentração do carbonato de cálcio.

3 - A tendência de alternância climática, como a passagem do clima úmido para o seco, evidenciada na evolução morfológica pós-cretácea brasileira (provavelmente no Plio-Pleistoceno), teria sido responsável pela evolução horizontal do modelado, dada a aceleração do recuo paralelo das vertentes por desagregação mecânica;

A abertura dos vales, tendo como nível de base os talvegues abandonados, teria proporcionado entulhamento do próprio nível de base, com tendência de elaboração de pediplano intermontano. Enquanto o clima úmido, por meio do entalhamento dos talvegues, teria respondido pela evolução vertical da morfologia, o clima seco tenderia a destruir as formas criadas pelo clima úmido, proporcionando a evolução horizontal da morfologia, caracterizando, deste modo, mais uma das relaçóes antagônicas da natureza.

Acredita-se ser esse o período geológico em que ocorrem as aplainaçôes neogênicas (AB'SABER, 1969b), originando os baixos chapadóes do Oeste Paulista, as quais o Planalto de Marília teria resistido. Enquanto há uma pediplanação generalizada no oeste do território paulista, na área estudada houve abertura dos vales - através do recuo paralelo das escarpas originadas pela incisão dos talvegues - por desagregação mecânica.

4 - Uma nova fase climática úmida ensejaria uma nova organização da drenagem e, conseqüentemente, um reentalhamento dos talvegues, proporcionando o alçamento de antigos depósitos, como os pedimentos detríticos que inumaram áreas depressionárias;

Tem-se, assim, o prosseguimento do trabalho evolutivo por erosão remontante e denudação dos topos interfluviais, com exumação parcial de camadas subjacentes resistentes, originando as superfícies estruturais, ou simplesmente a esculturação dos sedimentos que compóem a camada sobrejacente, caracterizando as superfícies esculturais.

O trabalho comandado pelo sistema hidrográfico enseja a evoluçâo do relevo via erosão regressiva, promovendo ramificaçôes de cursos de primeira ordem, podendo, então, aparecer formas residuais, como os morros-testemunhos, associados a materiais resistentes. As diferenças litológicas poderiam ainda proporcionar saliências morfológicas, parcialmente mascaradas na fase anterior, de clima seco, denominadas cornijas. Com a abertura dos vales, haveria uma tendência a se formarem vales simétricos, denominados vales em "manjedouras". A presença de pedimentos detríticos em processo de retrabalhamento morfológico pela incisão da drenagem é testemunha do clima seco correspondente à fase anterior. 


\section{5 - Consideraçóes finais}

O que se pode verificar é que os esforços tectônicos que culminaram com o extravasamento da Serra Geral, formação e evolução da Bacia Bauru, reativaçóes que resultaram em magmatismo alcalino e tectonismo pós-sedimentar (RICCOMINI, 1997), são reflexos de uma tectônica em escala espacial maior, em que há a ruptura do Gondwana, mas que apresentou influência pontual para a gênese do Planalto de Marília.

Há um aspecto importante a ressaltar devido a sua importância: os efeitos epirogenéticos sobre a evoluçáo do relevo. Segundo AB'SABER (1969a), durante todo o Terciário, o território do Estado de Sáo Paulo esteve em ascensão. De acordo com o autor (op. cit., p. 2), ao citar WASHBURNE (1930, p.114), essa epirogênese positiva corresponde a um "empinamento para oeste de toda a região da costa do Atlântico ao Rio Paraguai", cujo efeito foi a "aceleração dos rios de São Paulo que correm para o oeste". Ainda, no início do Pleistoceno, há uma aceleração do movimento ascencional, o que determinou "uma série de notáveis epigêneses em diversos setores dos grandes cursos d'água subparalelos do Oeste" (1969, p.3).

Acredita-se que essa aceleração dos rios a que se refere o autor (op. cit.), teria comandado a fragmentação do Planalto de Marília em três setores: Garça-Marília-Echaporã. Nessas áreas é possível verificar altos topográficos de formas tabulares semelhantes, destacadas na paisagem, recortadas pelas aplainaçóes neogênicas comandadas, principalmente, pelos rios do Peixe e Aguapeí, que correm em direção ao oeste e paralelos aos alinhamentos estruturais que cortam o embasamento cristalino no estado de Sáo Paulo.

O trabalho erosivo comandado por esses cursos d'água que se superimpuseram, foram os responsáveis pelas aplainaçóes terciárias e surgimento das superfícies neogênicas, das quais, os topos do Planalto de Marília testemunham e evidenciam antigos níveis das superfícies de erosão.

É possível de ser verificado, portanto, que há relações tectônicas e de sedimentação que influenciaram a evolução morfológica do Planalto de Marília. Todavia, não se atribui a esses aspectos papel de protagonista para a origem das formas atuais. $\mathrm{O}$ que se pretendeu foi chamar a atenção de que um conhecimento mais aprofundado da gênese desse Planalto não deve se restringir aos agentes externos de esculturação do relevo.

Agradecimentos - FAPESP (Fundação de Amparo a Pesquisa do Estado de São Paulo) pelo financiamento da pesquisa referente ao projeto de doutorado Cronogeomorfologia do relevo da cidade de Marília-SP através do método de traços de fissão.

\section{Referências Bibliográficas}

AB'SABER, A. N. (1969 a) - Ritmo da epirogênese pós-cretácica e setores das superfícies neogênicas em São Paulo. Geomorfologia, 13, p. 1-20.

AB’SABER, A. N. (1969 b) - Os baixos chapadóes do Oeste Paulista. Geomorfologia, 17, p. 1-8.

BARCELOS, J. H. (1984) - Reconstrução Paleogeográfica da Sedimentação do Grupo Bauru Baseada na sua Redefinição Estratigráfica Parcial em Território Paulista e no Estudo Preliminar Fora do Estado de São Paulo. Tese de Livre Docência, Inst. Geociências e Ciências Exatas, UNESP, Rio Claro, 190 p. 
BATEZELLI, A. (2003) - Análise da sedimentação cretácea no Triângulo Mineiro e sua correlação com áreas adjacentes. Tese de Doutorado, Inst. Geociências e Ciências Exatas, UNESP, Rio Claro, 183 p.

BATEZElli, A., GOMES, N. S. \& PERINOTTO, J. A. J. (2005) - Petrografia e evolução diagenética dos arenitos da porção norte e nordeste da Bacia Bauru (Cretáceo Superior). Revista Brasileira de Geociências, 35, p. 311-322.

BORGHI, L. (2002) - Fácies, arquitetura deposicional, tempestitos e o Devoniano da bacia do Paraná. Rio de Janeiro, Programa de Pós-graduação em Geologia, Universidade Federal do Rio de Janeiro, Tese de Doutorado, 309 p.

CASSETI, V. (2001) - Elementos de geomorfologia. Goiânia: Editora da UFG, 137 p.

ETCHEBEHERE, M. L. C., SAAD, A. R., FÚlfarO, V. J. \& PERINOTTO, J. A. J. (2004) - Aplicação do Índice "Relação Declividade-Extensão - RDE na Bacia do Rio do Peixe (SP) para Detecção de Deformaçóes Neotectônicas. Revista do Instituto de Geociências-USP, Geol. USP Sér. Cient., 4, p. 43-56.

FERNANDES, L. A. (2010) - Calcretes e registros de paleossolos em depósitos continentais neocretáceos (Bacia Bauru, Formação Marília). Revista Brasileira de Geociências, 40, p. 19-35, mar.

FÚlFARO, V. J. (1974) - Tectônica do Alinhamento Estrutural do Paranapanema. Boletim IG. Instituto de Geociências, USP, V, p. 129-138.

GRAVINA, E. G., KAFINO, C. V., BROD, J. A., BOAVENTURA, G. R., SANTOS, R. V., GUIMARÃES, E. M. \& JOST, H. (2002) - Proveniência de arenitos das formaçóes uberaba e marília (grupo bauru) e do garimpo do bandeira: implicaçóes para a Controvérsia sobre a fonte do diamante do triângulo mineiro. Revista Brasileira de Geociências, 32, p. 545-558.

IPT (INSTITUTO DE PESQUISAS TECNOLÓGICAS DO ESTADO DE SÃO PAULO) (1981) - Mapa geológico do Estado de São Paulo: 1:500.000. São Paulo: IPT, vol. I, p. 46-8; 69 (Publicação IPT 1184).

PAUlA e SILVA, F., CHANG, H. K. \& CAETANO-CHANG, M. R. (2003) - Perfis de referência do grupo bauru (K) no estado de São Paulo. Geociências, São Paulo, UNESP, 22, p. 21-32.

RICCOMINI, C. (1997) - Arcabouço estrutural e aspectos do tectonismo gerador e deformador da bacia Bauru no estado de São Paulo. Rev. Bras. Geoc., 27, p. 153-162.

ROSS, J. L. S. \& MOROZ, I. C. (1996) - Mapa geomorfológico do Estado de São Paulo. Revista do Departamento de Geografia, São Paulo, 10, p. 41-56.

SANTOS, C. A. M. (2009) - O relevo e o sistema de afastamento e tratamento de esgoto da cidade de Marília-SP. 196 f. Dissertação (Mestrado em Geografia) - Faculdade de Ciências e Tecnologia, Universidade Estadual Paulista, Presidente Prudente.

SOARES, P. C., LANDIM, P. M. B., FULFARO, V. J. \& SOBREIRO NETO, A. F. (1980) - Ensaio de caracterização estratigráfica do Cretáceo no Estado de São Paulo: Grupo Bauru. Revista Brasileira de Geociências, 10, p. 177-185.

SUGUIO, K. (1973) - Formação Bauru: calcários e sedimentos detríticos associados. Inst. de Geociências, Universidade de São Paulo, Tese Livre Docência, 2v. 